\author{
Available online at http://bajas.edu.iq \\ https://doi.org/10.37077/25200860.2019.265 \\ College of Agriculture, University of Basrah
}

Basrah Journal of

Agricultural

Sciences

ISSN $1814-5868$

Basrah J. Agric. Sci., 32(Spec. Issue 2): 156-170, 2019

E-ISSN: 2520-0860

\title{
Effect of Rainfall Quantity on the Frequency of Severe Dust Storm in Iraq
}

\author{
Ibrahim I. Mohammed ${ }^{1 *}$ \& Ahmed F. Hassoon ${ }^{2}$ \\ ${ }^{1}$ Department of Forecasting Atmospheric, Iraqi Meteorological Organization and Seismology, \\ Baghdad, Iraq. \\ 2 Department of Atmospheric, College of Science, University of Mustansiriyah, Iraq \\ *Corresponding author e-mail: altamimiibraheem85@gmail.com \\ Received 19 September 2019; Accepted 18 November 2019; Available online 22 November 2019
}

\begin{abstract}
The dust storms and their recurrence are common phenomena in Iraq because it suffers from the exploitation of mankind to the natural environment and to the deterioration of vegetation and soil which responsible to the exposure of the soil to wind erosion leading to dust phenomena. Rain is one of the most influential climatic elements in reducing and minimizing the impact of dust storms. The amount of rainfall in Iraq is relatively small, where most of the year is not rainy. This in turn increases the dryness of the soil and increases the formation of dust storms. In this research data of (visibility, wind speed and direction and total rain amount) from the Iraqi Meteorological Organization and Seismology were analyzed for nine stations spread across the country (Mosul, Kirkuk, Haditha, Baghdad, Rutba, Nukhayb, Najaf, Amara and Nasiriya) for the period from 2001 - 2017 to compare annually severe dust storms with rainy seasons. Drought seasons were also determined using the percent of normal rainfall (PN) method. It was found that there was an inverse relationship between rainfall and severe dust storms, (according to Pearson's correlation coefficient) where it was noticed that the highest amount of rainfall was in Mosul station with a total of $5231.6 \mathrm{~mm}$ during the study period with only 6 severe dust storms during the same period. In other hand the lowest amount of rainfall was in Nukhayb station $1304.6 \mathrm{~mm}$ during the study period with 62 severe dust storms.
\end{abstract}

Keyword: Dust storms, Severe, Rainfall, Visibility, Drought, Seasons.

\section{Introduction}

Dust storm is a common meteorological phenomenon in arid and semi-arid regions. Dust storms arise when a gust front or other strong wind blows on a dry surface. Particles on surface transported by siltation, creeping and suspension, process that moves soil from one place and deposits it in another (Jasper et $a l .$, 2012). Rain is considered to be the most important factor affecting on the cohesion of dust particles with each other beside affecting the growth of vegetation, so its protect the soil from the wind effect. As a result of this, dust 
storms will occur in areas with little rainfall and little vegetation such as the desert. therefore, after (24-36) hours from the last rainfall, no dust construction (Laith, 2009). Many studies in this field is done to relied drought with dust frequency, for example drought was can be determined using the Standardized Precipitation Index (SPI) applied to 36-year-long datasets (1977-2012) from four stations (Baghdad, Hai, Diwaniyah and Nasiriya). Overall drought intensities have increased significantly from 2008 - 2012 at all weather stations, and proportional with high dust frequencies (Ismael et al., 2019). In neighboring countries such as Iran, a relationship noted between increasing dust storm events and drought occurrence and wind speed has severely intensified dustiness in the region (Abbas et al., 2010).

\section{Characteristics of Dust Types}

The dust cases are divided into several types depending on the horizontal visibility, wind speed, and particles diameters (Mohammed, 2010).

\section{Suspended Dust (SD)}

Small, lightweight particles that have a diameter less than $1 \mu \mathrm{m}$ remain suspended in the air for several hours or days with quiet winds of about a speed (0-7 m.sec $\left.{ }^{-1}\right)$ and the horizontal visibility ranges from (0 - less than 10000) $\mathrm{m}$ (Mohammed, 2010). This kind of dust appear after dust storms and rising dust, where micro particles stay at air for several hours and sometimes extend for several days (Rashed, 2015).

\section{Rising Dust (RD)}

Small particles, that diameter varies from (110) $\mu \mathrm{m}$ rise to the top as a result of the lack of stability of the atmosphere due to sudden changes in the pressure gradient and the high surface temperature, resulting thermal eddies that raise the dust to the top and then fall again when the wind speed is about $8 \mathrm{~m} \cdot \mathrm{sec}^{-1}$ and more and the range of horizontal visibility varies from 1 - less than $10000 \mathrm{~m}$ (Rashed, 2015).

\section{Dust Storms (DS)}

It is a small granule, not exceed $100 \mu \mathrm{m}$, formed at high winds of about $8 \mathrm{~m} \cdot \mathrm{sec}^{-1}$, it can also load from the decayed soil in dry areas. These winds raise the dust to high altitudes, and reduction of the horizontal visibility to less than $1000 \mathrm{~m}$, where the front of the dust storm rises like a high wall, which rises to about $3000 \mathrm{~m}$ and widths of tens or even hundreds of kilometers. Dust storms are more frequent in the summer half, in the driest months, and the most severe in the wind. Although horizontal visibility is the indicator of the dust storm to this, it is necessary to have active winds, so that it can carry large amounts of dust to long distances. Dust storms are calculated on the basis of the number of days in which they occur monthly (Mohammed, 2014).

\section{Sand Storms (SS)}

The particles of sand storm which have big size with diameter $250 \mu \mathrm{m}$ and the sand consider the basic material. It needs high wind speed to formation. Frequently occur in south of Iraq (Mohammed, 2010).

\section{Classification of Dust Storms}

Dust storms can be classified for three types (Halos, 2017):

Light Dust Storm: is the storm that has horizontal visibility ranges from $(500<$ visibility $<1000) \mathrm{m}$, and the associated wind speed ranges from $(8<$ wind speed $\leq 10)$ $\mathrm{m} \cdot \mathrm{sec}^{-1}$.

Moderate Dust Storm: is the storm that has horizontal visibility ranges from $(200<$ visibility $\leq 500) \mathrm{m}$, and the associated wind speed ranges from $(8<$ wind speed $\leq 12)$ m.sec ${ }^{-1}$. 
Severe Dust Storm: is the storm that has horizontal visibility ranges from $(0 \leq$ visibility $\leq 200) \mathrm{m}$, and the associated wind speed ranges from $(8<$ wind speed $\leq 18) \mathrm{m} \cdot \mathrm{sec}^{-1}$.

Severe dust storms can be a serious hazard mainly to ground and air transportation and even to human health, because of increased particulate matter in air (Houssos et al., 2015).

\section{Relationship between rain and dust storms}

The rain is precipitated in the form of liquid water drops that have diameters greater than that of drizzle (Donald, 2015). Rainfall is one of the most important atmospheric phenomena. It has a strong impact on the global-scale atmospheric circulation as well as on local weather. The atmosphere is receiving the heat energy (that balance its net radiative energy loss), about 70 to 85 percent is latent heat released by the formation of precipitation (Werner \& Christian, 2003). The rain is considered to be the most important factor affecting on the cohesion of dust particles with each other beside affecting the growth of vegetation, so the last protect the soil from the wind effect, as a result of this dust storms will occur in areas with little rainfall and little vegetation such as the desert

$$
X=\frac{a_{1}+a_{2}+\cdots+a_{n}}{n}
$$

\section{Percent of normal}

The percent of normal rainfall is one of the simplest measurements index of rainfall to any location. Analyses using the percent of normal is very effective when used for a single region or a single season. Percent of normal is also easily misunderstood and gives different indications of conditions, depending on the location and season. It is calculated by dividing actual precipitation by a normal and in areas with poor rainfall. so after (2436) hours from the last rainfall, no dust (Laith, 2009). The rain considers the most important effecting factor to reduce the dust. In Iraq, the rainy season starts from the beginning of October to the ends of May except for the northern and northeastern parts where rainy season periods extend before and after the above months. In general, the amount of rainfall on Iraq is relatively few, most of the rainfall occurs during the period from November to March, due to the passage of air depressions coming from the Mediterranean Sea as well as the air depressions coming from the African-Arab Peninsula, which is heading towards the Iraq during the spring. The annual total of rainfall decreases from north to south and from east to west. Irregularity distribution in rainfall amount leads to soil erosion and helps to develop the phenomenon of dust and dust storms in Iraq (Mohammed, 1989).

\section{Materials \& Methods}

\subsection{The Average}

The average is the sum of all the values in a set, divided by the number of values. the mean of a sample is usually denoted by $\mathrm{x}$. (Keone, 2014)

rainfall (typically a 30-year mean) and multiplying this result by $100 \%$. This can be calculated for a variety of time scales. Usually these time scales range from a single month to a group of months representing a particular season, to an annual or water year. This method considers normal Rainfall to be $100 \%$ and less than this percentage is considered drought as shown in table (1) (Mannava et al., 2011). 
Mohammed \& Hassoon / Basrah J. Agric. Sci., 32(Spec. Issue 2):156-170, 2019

Table (1): Drought Rate Classification according to (PN) Method.

\begin{tabular}{|c|c|}
\hline Drought Type & Percentage $(\mathrm{PN})$ \\
\hline Moderate drought & $(100-50)$ \\
\hline Severe drought & $(50-25)$ \\
\hline Very severe drought & $(25<)$ \\
\hline
\end{tabular}

The drought index $(\mathrm{PN})$ is calculated for the percentage of precipitation through equation (1):

$$
P N=\left(P_{a c} / P_{\text {mean }}\right) * 100 \%
$$

where $\mathrm{I}$ is drought index, $P_{a c}$ is actual precipitation, and $P_{\text {mean }}$ is mean precipitation (Jasim, 2017).

\section{Pearson's correlation coefficient}

We make use of the linear product-moment correlation coefficient, also known as Pearson's correlation coefficient, to express the strength of the relationship. This

$$
r=\frac{n \sum x y-\sum x \sum y}{\sqrt{\left\{n \sum x^{2}-\left(\sum x\right)^{2}\right\}\left\{n \sum y^{2}-\left(\sum y\right)^{2}\right\}}}
$$

The value of $r$ always lies between -1 and 1 inclusive, that is, $-1 \leq \mathrm{r} \leq 1$. If $\mathrm{Y}$ increases when $\mathrm{X}$ increases, we say that there is positive or direct correlation between them. However, if $\mathrm{Y}$ decreases when $\mathrm{X}$ increases (or vice versa), then we say that they are negatively or inversely correlated. When $r=$ 0 , we may not assert that there is no correlation at all between $\mathrm{X}$ and $\mathrm{Y}$ (Michael, 2018). coefficient is generally used when variables are of quantitative nature, that is, ratio or interval scale variables. Pearson's correlation coefficient is denoted by $r$ and is defined by

\section{location:}

Iraq located between latitudes 29.5 - 37.22 degrees in north hemisphere, and between longitudes 38.42 - 48.45 degrees east from Greenwich line (Halos, 2017). In this study nine stations are selected in different area of Iraq map to represent the most of Iraq area as shown in fig. (1). 


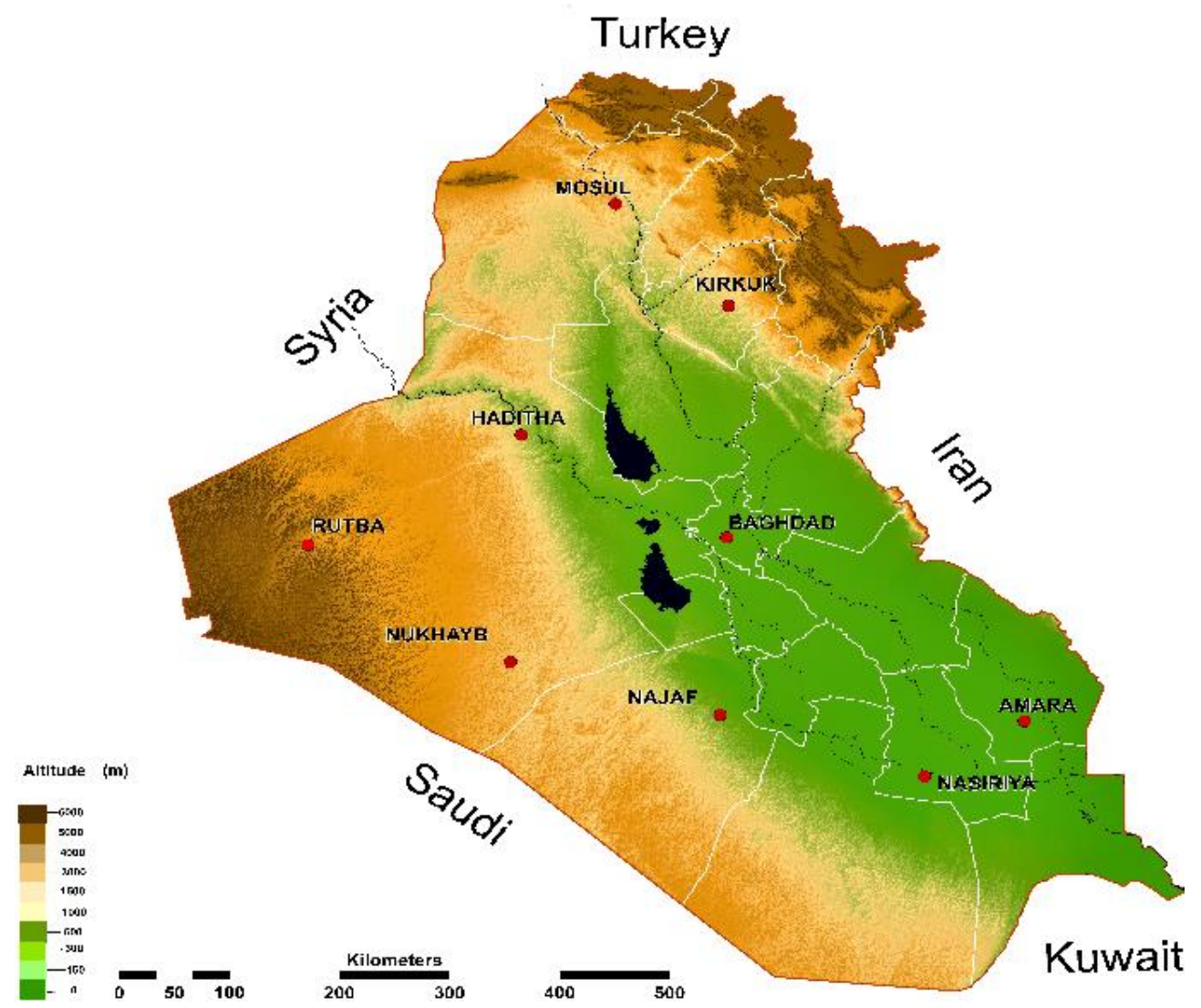

Fig. (1): Location of study stations of Iraq.

These stations are Mosul, Kirkuk and Haditha that represent the northern region and Baghdad, Rutba, and Nukhayb that represent the central region, and Najaf, Amara and Nasiriya that represent the southern region.
All data from these stations concerning Iraqi Meteorological Organization and Seismology (IMOS) and table (2) showed detail information about these stations.

Table (2): Information of stations of Iraq.

\begin{tabular}{|c|c|c|c|c|c|}
\hline $\begin{array}{l}\text { Station } \\
\text { Name }\end{array}$ & Location & $\begin{array}{c}\text { Station } \\
\text { Number }\end{array}$ & $\begin{array}{c}\text { Height } \\
\text { (m) }\end{array}$ & Latitude & Longitude \\
\hline Mosul & \multirow{3}{*}{ North } & 608 & 223 & 36.19 & 43.09 \\
\hline Kirkuk & & 621 & 331 & 35.28 & 44.24 \\
\hline Haditha & & 634 & 108 & 34.08 & 42.21 \\
\hline Nukhayb & \multirow{3}{*}{ Centre } & 658 & 305 & 32.02 & 42.17 \\
\hline Rutba & & 642 & 630.8 & 33.02 & 40.17 \\
\hline Baghdad & & 650 & 31.7 & 33.18 & 44.24 \\
\hline Najaf & \multirow{3}{*}{ South } & 670 & 53 & 31.57 & 44.19 \\
\hline Nasiriya & & 676 & 5 & 31.01 & 46.14 \\
\hline Amara & & 680 & 9.5 & 31.50 & 47.10 \\
\hline
\end{tabular}




\section{Data}

Data used in this study is based on the data recorded by the IMOS for the period 20012017. These data included hourly meteorological observations in general, and are especially dependent on both the range of visibility, wind speed and direction to identify for severe dust storms. Data recorded also included the total amount of monthly rainfall.

\section{Result \& Discussion}

\section{Yearly frequency of severe dust storm}

The yearly frequency of severe dust storms is calculating for the nine stations selected from 2001 to 2017 except for 2003 due to the war (second Arab Gulf), as shown in the table (5).

Nukhayb Station, the yearly frequency of severe dust storms during the study period was 62 days during 11 years. It is considered the highest frequency of severe dust storms among the selected stations for the study and the highest frequency was 15 days in 2009.

Amara station, the yearly frequency of severe dust storms during the study period was only four days during two years, which is considered the lowest frequency of severe dust storms among the selected stations for the study, and the highest frequency was 3 days in 2001, as shown in fig. (2).

\section{Rain and severe dust storms}

By using the seasonal rainfall data (in $\mathrm{mm}$ ) for the period (1988 - 2018) from the IMOS of the selected study stations (Mosul, Kirkuk, Haditha, Rutba, Baghdad, Nukhayb, Najaf, Amara and Nasiriya) whereas the rainy season in Iraq starts from the 9th month (September) until the 5th month (May). By using equation (1) to calculate the total average and process the missing data and taking the total average (monthly average of the rainy season which has the missing data then compute the rainy season by summing the monthly values) as shown in the table (3) as an example for this method, Baghdad station. 
Mohammed \& Hassoon / Basrah J. Agric. Sci., 32(Spec. Issue 2):156-170, 2019
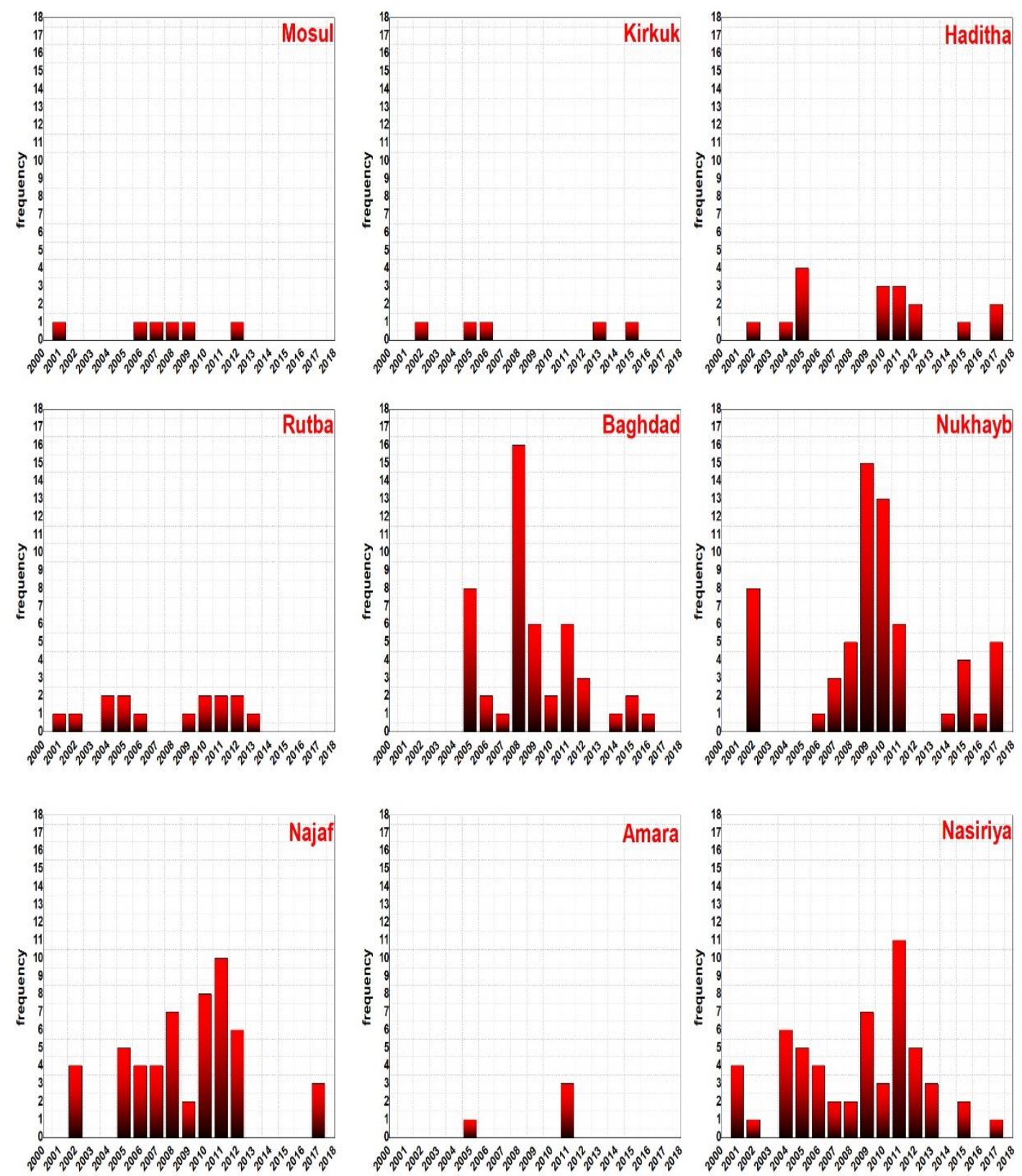

Fig. (2): Yearly frequency severe dust storms at (2001-2017).

Table (3): Missing rainfall data by using total average method for Baghdad station, M: missing data.

\begin{tabular}{|c|c|c|c|c|c|c|c|c|c|c|}
\hline Season & Sep. & Oct. & Nov. & Dec. & Jan. & Feb. & Mar. & Apr. & May. & Sum. \\
\hline $\mathbf{2 0 0 2 - 2 0 0 3}$ & 0 & 3.3 & 6.1 & 15 & $\mathrm{M}$ & $\mathrm{M}$ & $\mathrm{M}$ & $\mathrm{M}$ & $\mathrm{M}$ & $\mathrm{M}$ \\
\hline $\mathbf{1 9 8 8 - \mathbf { 2 0 1 8 }}$ & ------ & ------ & ----- & ----- & 24.5 & 14.7 & 17.4 & 13.8 & 3.4 & ----- \\
\hline $\begin{array}{c}\mathbf{2 0 0 2 - 2 0 0 3} \\
\text { After } \\
\text { Compensation }\end{array}$ & 0 & 3.3 & 6.1 & 15 & 24.5 & 14.7 & 17.4 & 13.8 & 3.4 & 98.4 \\
\hline
\end{tabular}


After that the averages for the period (1988 -2018) for each study stations were calculated by the monthly summation for each rainy season and then take the total summation average for all the rainy seasons for each station to get the general average as shown in table (4).

Table (4): The general average of the study stations.

\begin{tabular}{|l|c|c|c|c|c|c|c|c|c|}
\hline Stations & Mosul & Kirkuk & Haditha & Rutba & Baghdad & Nukhayb & Najaf & Amara & Nasiriya \\
\hline General & 334.8 & 333.4 & 120.5 & 115.4 & 123.7 & 80.1 & 92.9 & 175.9 & 122.1 \\
Average & & & & & & & & & \\
\hline
\end{tabular}

\section{Calculate drought seasons}

To calculate the meteorological drought seasons by (PN) method using equation (2) by dividing the actual rainfall of each season of the study (2001-2017) by the total average for 30 years and multiplying the output by (100\%), the monthly rainfall from each year started at September from one year and ended in May at the next year thus, all the normal rainfall seasons consist of the two years. After determining the meteorological drought seasons which have less than $100 \%$ and selecting the normal rainfall seasons which have $100 \%$ and more, it was compared with the frequency of severe dust storms for the same period for all the study stations (divided to north, center, south) as shown in fig. (3-a), (3-b) and (3-c).

It was noticed that the highest values of rainfall were at Mosul, Kirkuk, Amara, Baghdad, Nasiriya, Haditha, Rutba, Najaf and Nukhayb stations, respectively.

According to table (2), rainy seasons are divided to normal rainfall, moderate drought, Severe drought and very severe drought. It is noticed from table (5) that in the Northern region stations, Mosul had 6 normal rainfall seasons with 1 severe dust storm during them, 10 moderate drought seasons with 4 severe dust storms during them and 1 severe drought season with 1 severe dust storm during it.

Kirkuk station there were 7 normal rainfall seasons with 3 severe dust storms during them, 8 moderate drought seasons with 2 severe dust storms during them, and 2 severe drought seasons without any severe dust storm during them.

Haditha station, there were 5 normal rainfall seasons with 1 severe dust storms during them, 10 moderate drought seasons with 13 severe dust storms during them, and 2 severe drought seasons with 3 severe dust storms during them.

It is noticed that in the central region stations, Rutba there are 4 normal rainfall seasons with 1 severe dust storm during them, 8 moderate drought seasons with 10 severe dust storms during them. 4 severe drought seasons with 4 severe dust storms during them and 1 very severe drought season but no severe dust storm happened during it. 
Mohammed \& Hassoon / Basrah J. Agric. Sci., 32(Spec. Issue 2):156-170, 2019
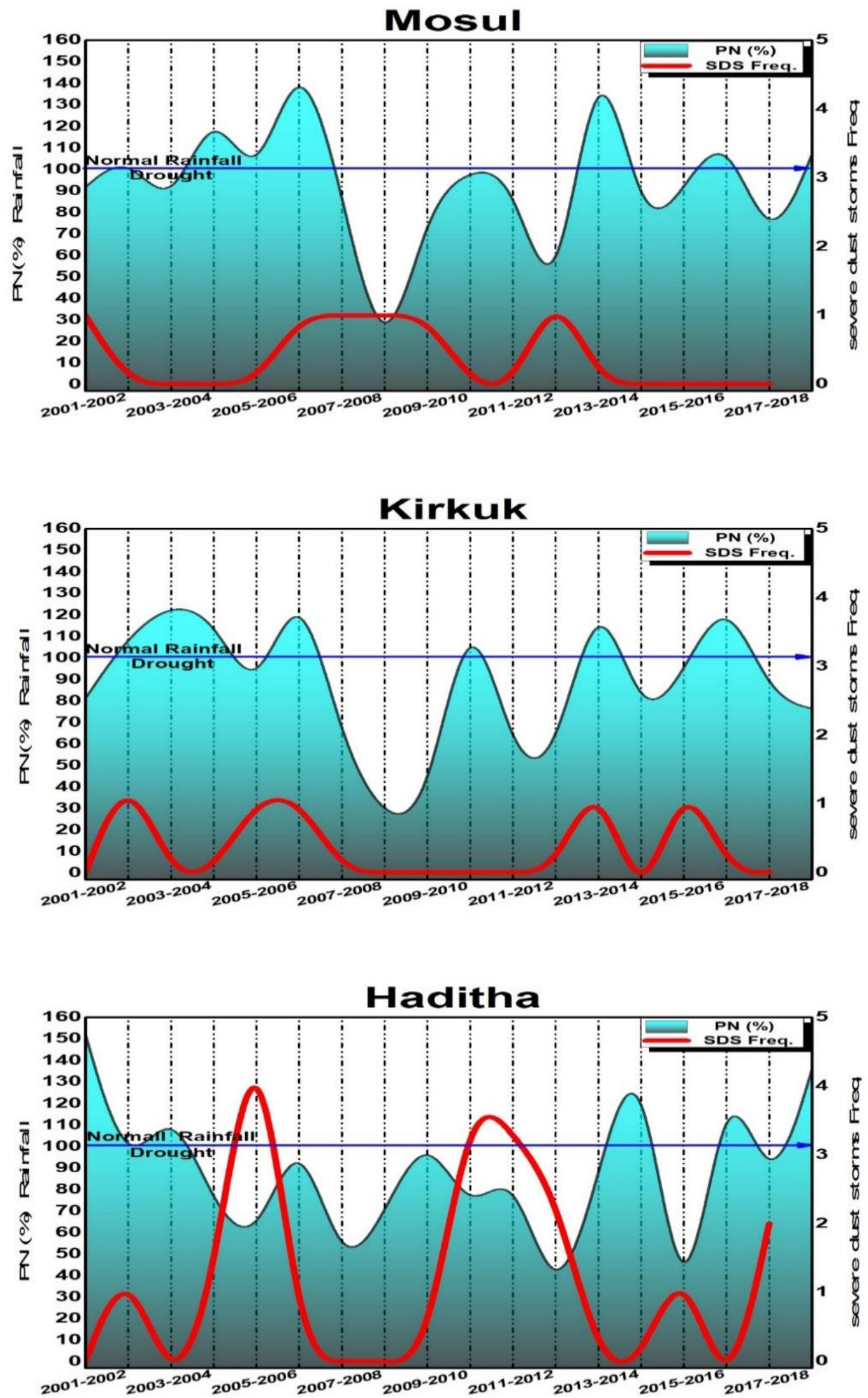

Fig. (3-a): Percentage of normal rainfall and frequency of severe dust storms for stations (Mosul, Kirkuk and Haditha) 
Mohammed \& Hassoon / Basrah J. Agric. Sci., 32(Spec. Issue 2):156-170, 2019

\section{Rutba}


Fig. (3-b): Percentage of normal rainfall and frequency of severe dust storms for stations (Rutba, Baghdad and Nukhayb). 
Mohammed \& Hassoon / Basrah J. Agric. Sci., 32(Spec. Issue 2):156-170, 2019
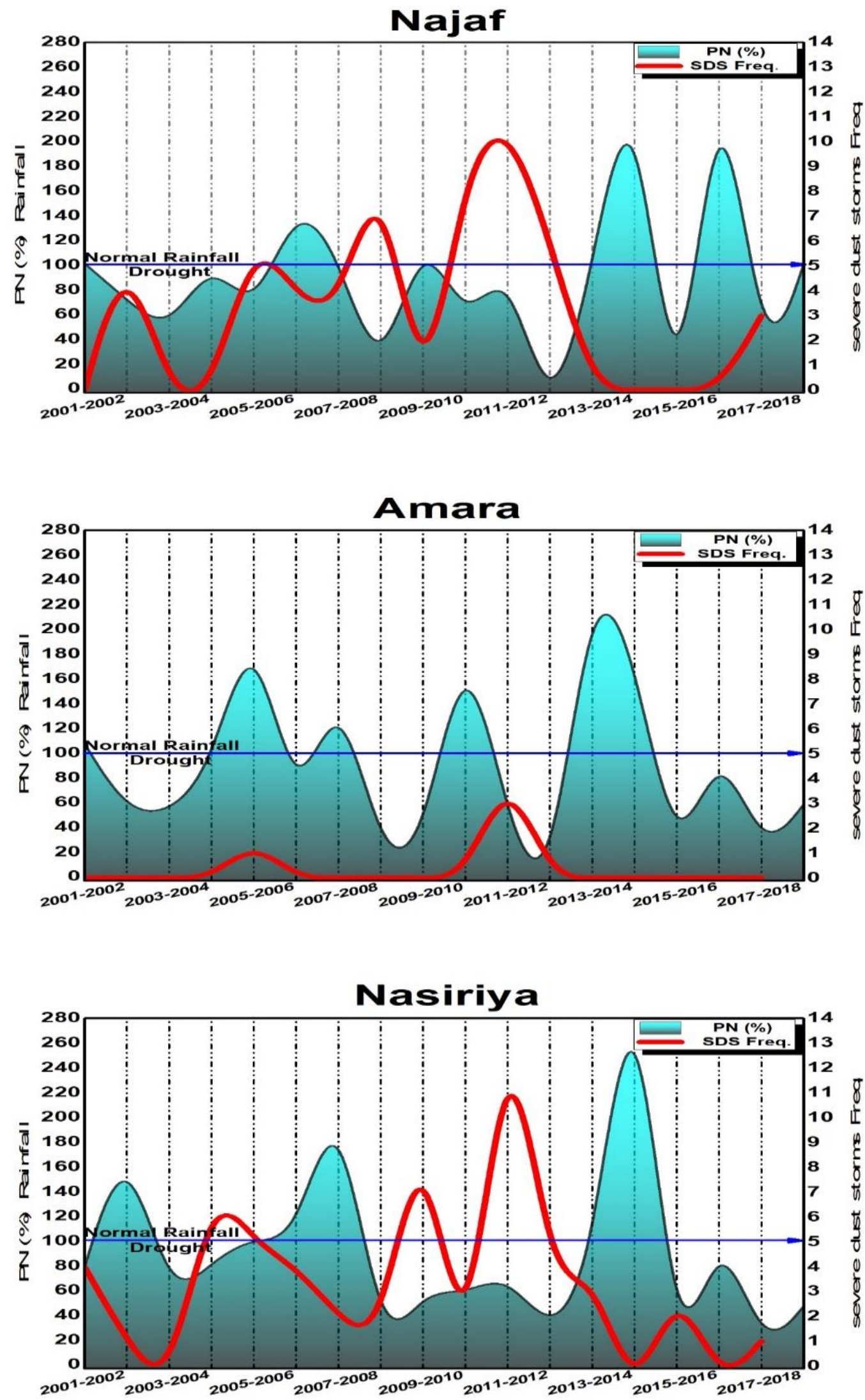

Fig. (3-c): Percentage of normal rainfall and frequency of severe dust storms for stations (Najaf, Amara and Nasiriya). 
Mohammed \& Hassoon / Basrah J. Agric. Sci., 32(Spec. Issue 2):156-170, 2019

Table (5): Rain Sum, Percentage of Normal Rainfall (PN) and Severe Dust Storms in the Study Period at Selected Stations

\begin{tabular}{|c|c|c|c|c|c|c|c|c|c|c|c|c|c|c|c|c|c|c|}
\hline Stations & Years & 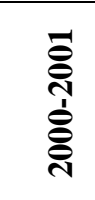 & 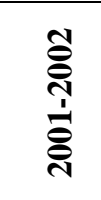 & 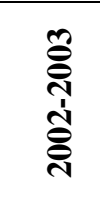 & 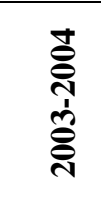 & 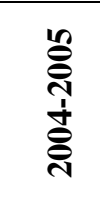 & 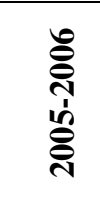 & 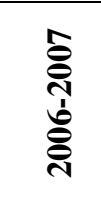 & 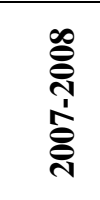 & 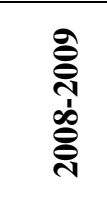 & 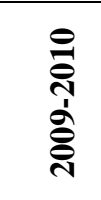 & 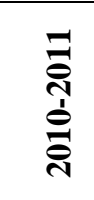 & 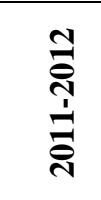 & 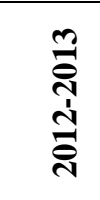 & 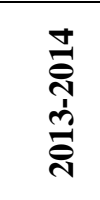 & 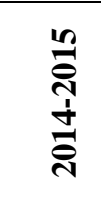 & 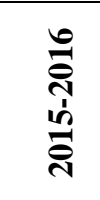 & 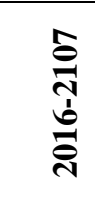 \\
\hline \multirow{3}{*}{ Mosul } & Rain sum. & 307.4 & 339.3 & 299.4 & 399.9 & 353.8 & 460.2 & 300.0 & 97.2 & 214.6 & 323.1 & 306.6 & 178.7 & 451.8 & 293.9 & 304.5 & 361.7 & 239.5 \\
\hline & $\mathrm{PN} \%$ & 91.8 & 101.3 & 89.4 & 119.4 & 105.7 & 137.4 & 89.6 & 29.0 & 64.1 & 96.5 & 91.6 & 53.4 & 134.9 & 87.8 & 90.9 & 108.0 & 71.5 \\
\hline & SDS freq. & 1 & 0 & 0 & 0 & 0 & 1 & 1 & 1 & 1 & 0 & 0 & 1 & 0 & 0 & 0 & 0 & 0 \\
\hline \multirow{3}{*}{ Kirkuk } & Rain sum & 270.7 & 357.8 & 405.9 & 381.6 & 307.1 & 400.3 & 232.8 & 112.6 & 124.0 & 358.7 & 210.4 & 197.6 & 394.1 & 277.5 & 310.5 & 399.9 & 299.1 \\
\hline & $\mathrm{PN} \%$ & 81.2 & 107.3 & 121.7 & 114.4 & 92.1 & 120.0 & 69.8 & 33.8 & 37.2 & 107.6 & 63.1 & 59.3 & 118.2 & 83.2 & 93.1 & 119.9 & 89.7 \\
\hline & SDS freq. & 0 & 1 & 0 & 0 & 1 & 1 & 0 & 0 & 0 & 0 & 0 & 0 & 1 & 0 & 1 & 0 & 0 \\
\hline \multirow{3}{*}{ Haditha } & Rain sum & 183.6 & 121.0 & 132.6 & 96.0 & 76.6 & 110.7 & 63.5 & 76.0 & 118.8 & 93.8 & 97.6 & 52.7 & 91.9 & 150.0 & 59.7 & 145.0 & 113.1 \\
\hline & $\mathrm{PN} \%$ & 152.3 & 100.4 & 110.0 & 79.6 & 63.5 & 91.8 & 52.7 & 63.0 & 98.5 & 77.8 & 81.0 & 43.7 & 76.2 & 124.8 & 49.5 & 120.3 & 93.8 \\
\hline & SDS freq. & 0 & 1 & 0 & 1 & 4 & 0 & 0 & 0 & 0 & 3 & 3 & 2 & 0 & 0 & 1 & 0 & 2 \\
\hline \multirow{3}{*}{ Rutba } & Rain sum & 159.8 & 36.7 & 146.5 & 97.1 & 112.8 & 95.4 & 115.9 & 27.5 & 51.4 & 101.6 & 102.3 & 23.1 & 87.1 & 201.4 & 91.6 & 111.6 & 31.7 \\
\hline & $\mathrm{PN} \%$ & 138.5 & 31.8 & 127.0 & 48.1 & 97.7 & 82.6 & 100.4 & 23.8 & 44.5 & 88.0 & 88.7 & 27.8 & 75.5 & 174.5 & 97.4 & 96.7 & 27.5 \\
\hline & SDS freq. & 1 & 1 & 0 & 2 & 2 & 1 & 0 & 0 & 1 & 2 & 2 & 2 & 1 & 0 & 0 & 0 & 0 \\
\hline \multirow{3}{*}{ Baghdad } & Rain sum & 106.9 & 84.2 & 98.4 & 122.5 & 141.1 & 141.4 & 125.9 & 37.6 & 52.2 & 94.7 & 121.1 & 29.3 & 263.6 & 278.1 & 72.7 & 219.3 & 100.3 \\
\hline & $\mathrm{PN} \%$ & 86.4 & 68.0 & 79.5 & 99.0 & 114.0 & 114.3 & 101.7 & 30.4 & 42.2 & 76.5 & 97.9 & 23.7 & 213.0 & 224.7 & 58.8 & 177.2 & 81.1 \\
\hline & SDS freq. & 0 & 0 & 0 & 0 & 8 & 2 & 1 & 16 & 6 & 2 & 6 & 3 & 0 & 1 & 2 & 1 & 0 \\
\hline \multirow{3}{*}{ Nukhayb } & Rain sum & 105.0 & 102.4 & 88.2 & 86.3 & 58.7 & 38.6 & 61.2 & 53.3 & 13.5 & 110.8 & 85.5 & 86.3 & 84.0 & 85.2 & 39.9 & 142.6 & 62.9 \\
\hline & $\mathrm{PN} \%$ & 131.0 & 127.8 & 110.1 & 107.7 & 73.2 & 48.2 & 76.4 & 66.5 & 16.8 & 138.2 & 106.7 & 107.7 & 104.8 & 106.3 & 49.8 & 177.9 & 78.5 \\
\hline & SDS freq. & 0 & 8 & 0 & 0 & 0 & 1 & 3 & 5 & 15 & 13 & 6 & 0 & 0 & 1 & 4 & 1 & 5 \\
\hline \multirow{3}{*}{ Najaf } & Rain sum & 94.3 & 68.0 & 54.0 & 84.3 & 75.6 & 125.3 & 97.1 & 36.1 & 91.4 & 67.4 & 74.8 & 10.2 & 90.8 & 184.5 & 42.7 & 183.3 & 57.8 \\
\hline & $\mathrm{PN} \%$ & 101.5 & 73.2 & 58.1 & 90.7 & 81.4 & 134.8 & 104.5 & 38.8 & 98.4 & 72.5 & 80.5 & 11.0 & 97.7 & 198.5 & 45.9 & 197.2 & 62.2 \\
\hline & SDS freq. & 0 & 4 & 0 & 0 & 5 & 4 & 4 & 7 & 2 & 8 & 10 & 6 & 0 & 0 & 0 & 0 & 3 \\
\hline \multirow{3}{*}{ Amara } & Rain sum & 190.1 & 109.9 & 105.5 & 169.8 & 291.8 & 159.7 & 214.2 & 75.9 & 80.0 & 265.4 & 109.3 & 36.9 & 353.2 & 317.7 & 83.7 & 146.1 & 70.0 \\
\hline & PN \% & 108.0 & 62.4 & 59.9 & 96.5 & 165.8 & 90.7 & 121.7 & 43.1 & 45.5 & 150.8 & 62.1 & 21.0 & 200.7 & 180.5 & 47.6 & 83.0 & 39.8 \\
\hline & SDS freq. & 0 & 0 & 0 & 0 & 1 & 0 & 0 & 0 & 0 & 0 & 3 & 0 & 0 & 0 & 0 & 0 & 0 \\
\hline \multirow{3}{*}{ Nasiriya } & Rain sum & 96.0 & 181.4 & 93.9 & 101.6 & 126.8 & 142.2 & 216.2 & 54.1 & 65.2 & 74.0 & 79.9 & 48.8 & 125.7 & 307.8 & 66.2 & 99.8 & 42.2 \\
\hline & PN \% & 78.6 & 148.6 & 76.9 & 83.2 & 103.8 & 116.5 & 177.1 & 44.3 & 53.4 & 60.6 & 65.4 & 40.0 & 102.9 & 252.1 & 54.2 & 81.7 & 34.6 \\
\hline & SDS freq. & 4 & 1 & 0 & 6 & 5 & 4 & 2 & 2 & 7 & 3 & 11 & 5 & 3 & 0 & 2 & 0 & 1 \\
\hline
\end{tabular}


Baghdad station there are 6 normal rainfall seasons with 13 severe dust storms during them, 8 moderate drought seasons with 10 severe dust storms during them, 2 severe drought seasons with 22 severe dust storms during them and 1 very severe drought season with 3 severe dust storms during it.

Nukhayb station there are 10 normal rainfall seasons with 29 severe dust storms during them, four moderate drought seasons with 13 severe dust storms during them, two severe drought seasons with five severe dust storms during them and 1 very severe drought season with 15 severe dust storms during it.

It is noticed that in the southern region stations, Najaf there are five normal rainfall seasons with eight severe dust storms during them, nine moderate drought seasons with 32 severe dust storms during them, two severe drought seasons with seven severe dust storms during them and one very severe drought season with six severe dust storms during it.

Amara station there are six normal rainfall seasons with one severe dust storm during them, six moderate drought season with three severe dust storms during them, four severe drought season and 1 very severe drought season but no severe dust storm happened during them.

Nasiriya station there are 6 normal rainfall seasons with 15 severe dust storms during them, eight moderate drought seasons with 33 severe dust storms during them and three severe drought seasons with eight severe dust storms during them. by using the equation (3) Pearson's correlation coefficient, the results shown in the table

(6).

Table (6): Pearson's correlation coefficient between the Percentage of Normal Rainfall (PN) and severe dust storm.

\begin{tabular}{|c|c|}
\hline Stations & $\mathbf{R}$ \\
\hline Mosul & -0.55186 \\
\hline Kirkuk & 0.54159 \\
\hline Haditha & -0.0948 \\
\hline Baghdad & -0.55747 \\
\hline Rutba & 0.31125 \\
\hline Nukhayb & -0.73061 \\
\hline Najaf & -0.23392 \\
\hline Amara & 0.04094 \\
\hline Nasiriya & 0.02092 \\
\hline
\end{tabular}

\section{Conclusion}

The frequency of the annual data of the severe dust storms of the selected stations during the study period, 2011 was the most frequent year of severe dust storms, with 41 severe dust storms recorded. The years 2014 and 2016 are the least frequent, with two severe dust storms recorded for each year. Through the total rainfall data, it was found that the Mosul station is the most quantity and the Nukhayb station is the least quantity. 
After determining the seasons of drought and natural precipitation seasons, there was a positive relationship between the severe dust storms and drought seasons.

The highest frequency of severe dust storms per year during the study period was at Nukhayb, Nasiriya and Najaf stations, respectively (62, 56 and 53 days). While The lowest frequency per year was at Amara, Kirkuk and Mosul stations, respectively (4, 5 and 6 days).

The highest total amount of rainfall during the study period was at Mosul, Kirkuk and Amara Stations respectively (5522.637, 5295.452 and $2882.515 \mathrm{~mm}$ ). While The lowest total amount of rainfall during the study period was $1385.964,1528.343$ and $1752.178 \mathrm{~mm}$ at Nukhayb, Najaf and Rutba stations, respectively.

\section{Acknowledgements}

The senior author would like to thank the staff of the Department of Atmospheric Forecasting, Iraqi Meteorological Organization and Seismology. And thank the staff of the Department of Atmospheric Sciences, College of Science, the University of Mustansiriyah for support me during this work.

\section{References}

Abbas, M.; Alireza, M.; Ahmad, P. \& Naser P. (2010). Dust storm frequency after the 1999 drought in the Sistan region, Iran. Clim. Res., 41: 83-90.

Donald, A.C. (2015). Essentials of Meteorology. 7th ed. Cengage Learning, 544pp.

Halos, S.H. (2017). Impact of dust storms on aerosol optical depth over Iraq. Ph. D. thesis, Coll. Science, Univ. Mustansiriyah: $161 \mathrm{pp}$.

Houssos, E.E.; Chronis, T.; Fotidi, A. \& Hossain, F. (2015). Atmospheric circulation characteristics favoring dust outbreaks over the solar village. Central Saudi Arabia. Am. Meteor. Soc., 143, 3263-3275.

Ismael, D.S.A.; Rebecca, M.B. \& Stefan, E. (2019). Drought severity and increased dust storm frequency in the Middle East: A case study from the Tigris-Euphrates alluvial plain. Roy. Meteor. Soc., 99: 665667.

Jasper, F.K.; Eric, J.R.P.; Timothy, I.M. \& Diana, B.K. (2012). The physics of windblown sand and dust. Reports on Progress in Physics on December 21: 115pp.

Jasim, Z.H. (2017). Determination of dry seasons and Areas selected locations in Iraq using Geographic-Information system. M. Sc. Thesis, Coll. Sci., Univ. Mustansiriyah: 62pp. (In Arabic).

Keone, H. (2014). An introduction to statistics. Create space independent Publishing Platform. 44pp.

Laith, O. (2009). Determination of dust storm source areas in Iraq using (TOMS) data and surface data. M. Sc. Thesis, Coll. Sci., Univ. Mustansiriyah: 99pp. (In Arabic).

Mohammed, B.A. (1989). A study of dust storms in Iraq. M. Sc. Thesis, Coll. Sci., Univ. Mustansiriyah: 83pp. (In Arabic).

Mohammed, J.H. (2010). Dust storms and their relation with some meteorological parameters and synoptic patterns to selected stations in Iraq. Ph. D. thesis, Coll. Sci., Univ. Mustansiriyah: 176pp. (In Arabic).

Mohammed, T.H. (2014). The effect of dust storms on some meteorological variables in Baghdad city: Case studies. M. Sc. Thesis, Coll. Sci., Univ. Mustansiriyah: 94pp. (In Arabic).

Mannava, V.K.S.; Donald, A.W.; Mark, D.S.; Mike, H. \& Raymond. M. (2011). Drought 
Mohammed \& Hassoon / Basrah J. Agric. Sci., 32(Spec. Issue 2):156-170, 2019

risk and meteorological droughts. ISDR: $27 \mathrm{pp}$.

Michael, J.S. (2018). Statistical Analysis Handbook: A comprehensive handbook of statistical concepts, Techniques and software tools. The Winchelsea Press: 680pp.
Rashed, M.M. (2015). Study the effect of dust storms on the attenuation and polarization of microwaves. M. Sc. Thesis, Coll. Sci., Univ. Mustansiriyah: 105pp. (In Arabic).

Werner, A. \& Christian, M. (2003). Rainfall. SAR Marine User's Manual, 17: 355-371. 